\section{Place for all of the mammals}

\section{R.J.G. Savage}

Mammalian Paleofaunas of the World.

By Donald E. Savage and Donald E.

Russell.

Addison-Wesley: 1983. Pp.432. \$79.95, f55.20.

THIS book is set fair to become the most quoted work in mammalian evolution, palaeogeography and biostratigraphy. The authors set out to list every mammal genus and species with a fossil record, a task as unambiguous as it is formidable - more than 3,000 genera and at least twice that number of species, over a 200-million-year time-span, and spread across six continents (the discovery of a fossil marsupial in Antarctica came too late for inclusion).

However, this daunting task has been made lighter by the recent publication of major treatises on Mesozoic and Pleistocene mammals*. By dealing with these periods relatively briefly, the authors are left with the Tertiary faunas, one-third of the time span and $90 \%$ of the known taxa. North America and Europe get complete coverage though other continents are treated less fully. Thus South American faunas are mostly quoted at generic level; African faunas are not as up-to-date as they might be; Asiatic faunas are rather patchily covered and the Russian examples are especially poor. In listing faunal distribution on a continental basis, data at the generic level would have been adequate, but to make use of the specific listings, distribution must be known in more detail; herein lies a major weakness of the book.

The size of the time steps used are important in any faunal analysis. Here, the authors have wisely chosen the "mammal age" as their basic unit. Although these are very uneven in time span (ranging from 0.5 to 9 million years), they are widely recog nized and internationally agreed intervals. The text includes locality lists for each epoch, extensive bibliographies and, for most epochs, detailed justification for the choice of boundaries, even though the listings are based on the ages and not on the epochs.

In the final chapter the authors tabulate the distributional data for North American and European mammalian genera and families, providing graphs of the turnover rates and voicing (very softly) a few inter-

*Mesozoic Mammals. By J.A. Lillegraven, Z. Kielan-Jaworowska and W.A. Clemens. (University of California Press, 1979). Pleistocene Mammals of Europe. By B. Kurtén. (Weidenfeld \& Nicholson, 1968). Pleistocene Mammals of North America. By B. Kurtén and E. Anderson. (Columbia University Press, 1980). pretations and speculations.

Quite obviously this is a book to be referred to, not one to read. Nonetheless the text is quite understandable and in places even entertaining. There is a fondness for the second person (singular or plural?); you are treated to discussions on the biochorology, biogeography and palaeontogeography of fossil mammals. The maps are not wholly sucessful, however - no scale, no latitude or longitude, often much wasted space - and very few of them are based on palaeogeographical maps. There is a scattering of fossil illustrations, inserted one feels at the publisher's request; nearly all are from publications of the University of California Press, which at least has the merit of maintaining consistently high standards. The number of misprints is smallish and these are mostly trivial and obvious.

There has been no work for the past quarter of a century which has attempted to record the mammalian palaeofaunas of the world, and none at any time which has done the job in such painstaking detail. On these grounds alone we must be grateful to the authors for providing us with a highly reliable work, an indispensible reference source and a monumental data base from which to test our theories, be they evolutionary, faunal or geographical.

R.J.G. Savage is Professor of Vertebrate Palaeontology at the University of Bristol.

\section{Back to the ocean}

\section{R.W. Girdler}

The Ocean Basins and Margins: Vol. 6, The Indian Ocean.

Edited by Alan E.M. Nairn

and Francis G. Stehli.

Plenum: 1982. Pp.776. \$85, £59.50.

NINETEEN eighty-three marks the fiftieth anniversary of the Anglo-Egyptian Mabahiss-John Murray expedition to the Indian Ocean, the event being celebrated in Alexandria this September. The sixth volume of this series on ocean basins and margins thus makes a timely appearance. There have of course been earlier and more recent expeditions to the region; the first was by H.M.S. Challenger in the 1870 s, while in the 1960s there was the international Indian Ocean expedition in which some $\mathbf{4 0}$ ships from 13 nations took part.

The Indian Ocean best exemplifies continental drift. It was essentially formed by the break-up and drifting apart of Antarctica, Africa, India and Australasia. India drifted fastest, fairly rocketing north at nearly $10 \mathrm{~cm} \mathrm{yr}^{-1}$, crashing against Asia some $50 \mathrm{Myr}$ ago and resulting in the evolution of the Himalayas. The Seychelles stand as sialic relics indicating that the continental break-up was not always clean and making it easy to visualize continental drift, the islands being left behind as the major landmasses dispersed.

Somehow this weighty volume fails to capture the excitement of the exploration of the Indian Ocean and of the application of plate tectonics in the area. There are two notable exceptions - a comprehensive account of the aseismic ridges, spreading centres and basins by R. Schlich, and a fascinating review of the structure, tectonics and history of the north-eastern Indian Ocean by J.R. Curray and co-workers. The new charts and tectonic maps in these chapters are now very detailed, but it is remarkable how the 1965 physiographic diagram of the Indian Ocean by Heezen and Tharp stands the test of time. I happened to have been with Marie Tharp at the Lamont Geological Observatory the day she discovered the data were better fitted if all the fracture zones trended north-north-east instead of west-east as previously found in the Atlantic Ocean. This caused elation and dismay; elation at the discovery, dismay at the thought of having to re-do the whole chart! Now this all fits most beautifully into the plate tectonic picture.

The remaining chapters take us clockwise around the margins of the Indian Ocean. Starting with south-east Africa, the Somali Basin and east Africa, diversions into the Red Sea and Gulf of Aden, then the Persian Gulf, and follow on around the Indian continental margins, south-east Asia, western Australia, southern Australia and finally the Antarctic margin. The theme is broken by one chapter on oceanic islands and another on Madagascar. Apart from sialic fragments such as the Seychelles there are many volcanic islands in the Indian Ocean, and so I was hoping to discover from the contribution on oceanic islands how these have formed and how they are related to the sea-floor-spreading history, hot spots and so on. Alas, we find but an encyclopaedic account of the geology of the islands with few ideas of why they are there.

There are no introductory or concluding chapters and surprisingly, in view of the interests of the editors, no chapter on the palaeomagnetism of the continents surrounding the Indian Ocean to complement the accounts of the sea-floor-spreading history and plate tectonic setting. There are very comprehensive reference lists, but few citations post-1979.

Excitement may be missing, but the book certainly provides the reader with a feast of information. For those looking for such detail on the Indian Ocean and its margins this book will be of great value; for those wanting an overview of tectonic history and the evolutionary processes, the many papers which have appeared recently will be more useful.

R.W. Girdler is Reader in Geophysics in the School of Physics, University of Newcastle upon Tyne. 